\title{
Optimal Ordering and Pricing Policies for Seasonal Products: Impacts of Demand Uncertainty and Capital Constraint
}

\author{
Jinzhao Shi, ${ }^{1,2}$ Richard Y. K. Fung, ${ }^{2}$ and Ju'e Guo' \\ ${ }^{1}$ School of Management, Xian Jiaotong University, No. 28 Xianning West Road, Xian, Shaanxi 710049, China \\ ${ }^{2}$ Department of Systems Engineering \& Engineering Management, City University of Hong Kong, Tat Chee Avenue, \\ Kowloon, Hong Kong
}

Correspondence should be addressed to Ju’e Guo; guojue@mail.xjtu.edu.cn

Received 31 May 2016; Accepted 25 September 2016

Academic Editor: Jean J. Loiseau

Copyright (C) 2016 Jinzhao Shi et al. This is an open access article distributed under the Creative Commons Attribution License, which permits unrestricted use, distribution, and reproduction in any medium, provided the original work is properly cited.

\begin{abstract}
With a stochastic price-dependent market demand, this paper investigates how demand uncertainty and capital constraint affect retailer's integrated ordering and pricing policies towards seasonal products. The retailer with capital constraint is normalized to be with zero capital endowment while it can be financed by an external bank. The problems are studied under a low and high demand uncertainty scenario, respectively. Results show that when demand uncertainty level is relatively low, the retailer faced with demand uncertainty always sets a lower price than the riskless one, while its order quantity may be smaller or larger than the riskless retailer's which depends on the level of market size. When adding a capital constraint, the retailer will strictly prefer a higher price but smaller quantity policy. However, in a high demand uncertainty scenario, the impacts are more intricate. The retailer faced with demand uncertainty will always order a larger quantity than the riskless one if demand uncertainty level is high enough (above a critical value), while the capital-constrained retailer is likely to set a lower price than the well-funded one when demand uncertainty level falls within a specific interval. Therefore, it can be further concluded that the impact of capital constraint on the retailer's pricing decision can be influenced by different demand uncertainty levels.
\end{abstract}

\section{Introduction}

With rapid development of science and technology, more and more products become fashionable or seasonal goods with short sales cycle, low salvage value, and high demand uncertainty [1]. For instance, cut flowers, clothing, and even smartphones are all common products with fashionable or seasonal attributes, and inventory management of these products is crucial as well as complicated [2-4]. What is more, the vast of enterprises in the industry are small- and mediumsized enterprises (SMEs) often with shortage of liquid funds [5]. Especially under the influence of global financial crisis, massive enterprises all over the world suffer from capital shortage even bankruptcy, throughout manufacturers, distributors, and retailers. Therefore, in the latest decade, interfaces of operations and financial decisions receive substantial interest and the so called "capital-constrained newsvendor" problem is widely concerned [6].
Towards "capital-constrained newsvendor" problem, many scholars study the retailer's integrated decision on operations and financing in the presence of capital constraint, including studies on optimal order quantity [7], purchase timing $[8,9]$, and financing mode selection [10-12]. These researches are all based on classical newsvendor models where market prices and demand distributions are exogenously given. However, in most practical cases, market demands are price-dependent; thus characterizing price effect into the newsvendor problem is necessary $[2,13]$. For instance, demand uncertainty and demand-price elasticity of smartphones are both relatively high, so it is crucial for smartphone companies (e.g., Samsung, Huawei, and Xiaomi) to make an integrated decision on capacity and pricing before releasing a new smartphone to the market. With a random price-dependent market demand, the current paper combines pricing decision into the "capital-constrained newsvendor" problem and investigates retailer's integrated 
decisions on ordering, pricing, and financing, which is not observed in existing literature. The main contributions and conclusions of this paper are as follows.

(1) Studying Retailer's Integrated Decisions on Ordering, Pricing, and Financing. With introducing pricing decision into the "capital-constrained newsvendor" problem, this paper investigates the retailer's integrated ordering and pricing decisions in the presence of capital constraint. Results show that when market size is extremely small, the retailer will not borrow from the bank to order any quantity. Otherwise, it will borrow to order and its optimal order quantity and selling price can be uniquely determined.

(2) Investigating the Impacts of Demand Uncertainty and Capital Constraint on Retailer's Optimal Ordering and Pricing Policies. Three models (i.e., the riskless model, uncertainty model, and uncertainty-underfunded model) are developed and in-depth comparisons of optimal solutions in three models are carried out to reveal how demand uncertainty and capital constraint affect retailer's integrated ordering and pricing policies. The problems are studied in a low and high demand uncertainty scenario, respectively, which is differentiated by an ingenious method, and plenty of conclusions are obtained through both theoretical analyses and numerical studies.

The remainder of the paper is organized as follows. Section 2 presents the review of related literature. Section 3 describes the problem and provides the model notations and assumptions. Section 4 formulates three models and derives the optimal solutions. Section 5 compares optimal solutions in three models. Section 6 carries out numerical experiments to validate theoretic results. Section 7 explores the case with high demand uncertainty. Section 8 concludes and presents future research directions.

\section{Literature Review}

This paper is related to literature on "interface of operations and financing decisions" and "integrated decisions on operations and marketing." In this section, we review the most related literature and highlight the innovations of the current paper.

2.1. Interface of Operations and Financing Decisions. The interface of operations and financing decisions has attracted widely attention in recent years. The operation-finance interface contains a lot of categories and dimensions [14]. Among them, the "capital-constrained newsvendor problem (CCNP)" has been widely concerned. Xu and Birge [15] are the first to bring capital constraints into a simple newsvendor model and try to understand the impact of capital structure on the retailer's operational decisions. Buzacott and Zhang [16] firstly incorporate asset-based financing into production decisions.

Many researches focus on the impacts of financial constraint on retailer's ordering/inventory policy. Research results show that retailer's optimal ordering policy will not be influenced by financial constraint in the presence of a competitively priced lending market $[6,11,12,17]$, but it will be affected by retailer's internal capital level as well as loan interest rate when the retailer is faced with a noncompetitively priced lending market $[7,8]$.

For a retailer, aside from bank credit financing (BCF), trade credit financing (TCF) (e.g., a delay payment scheme provided by the supplier) is another commonly used financing mode to deal with short-term capital shortage problem (see the review paper of Molamohamadi et al. [18]). Jing et al. [10] and Jing and Seidmann [11] further compare the efficiency between BCF and TCF for a capital-constrained retailer, and it is found that when production cost is relatively low, TCF will be more effective than BCF in mitigating double marginalization. Cai et al. [19] prove that BCF and TCF are either complementary or substitutable for a capitalconstrained retailer through both theoretical and empirical studies.

Yan et al. [20] study the CCNP problem from a perspective of supply chain finance (SCF) system. The partial trade credit guarantee contract proposed by them can be regarded as the combination of BCF and TCF, under which the manufacturer shares a portion of the retailer's default risk for the bank. Other related researches extend the CCNP problem to various directions. For instance, Zhang et al. [21] consider a loss averse newsboy model with capital constraint, Katehakis et al. [22] tackle a dynamic multiperiod inventory management problem for a firm financed by bank loans, Wang et al. [23] investigate the optimal decisions and financing strategies of a capital-constrained manufacturer in the supply chain, and $\mathrm{Li}$ et al. [24] study the optimal financing decisions of two capital-constrained supply chains with complementary products.

All of the above researches are based on classical newsvendor models where market prices and demand distributions are exogenously given. However, with a stochastic price-dependent demand, the current paper combines marketing decision (i.e., pricing decision) into the "capitalconstrained newsvendor" problem and investigates how financial constraint affects retailer's integrated ordering and pricing decisions, which is not observed in existing literature.

2.2. Integrated Decisions on Operations and Marketing. In the context of integrated decisions on operations and marketing, many researches focus on the retailer's integrated ordering and pricing decisions under uncertain market demands. Whitin [25] is the first to formulate classical newsvendor model with price effect, where selling price and stocking quantity are set simultaneously. Mills [26] refines the formulation by explicitly specifying demand as a function of selling price. Petruzzi and Dada [13] present an overall review on incorporating pricing into the newsvendor model, and two main random price-dependent demand formulations, that is, additive demand case and multiplicative demand case, are further extended to fit multiple period problems. Van Mieghem and Dada [27] further enrich the models by considering postponement of decisions on ordering or pricing.

Based on these basic models, integrated decisions on ordering and pricing are investigated under different settings 
and perspectives, such as product return [2, 28], supply uncertainty [29], service level constraint [30, 31], multiple price markdowns [32], supply chain contracts [33, 34], dual sourcing channel $[35,36]$, and multiperiod planning [3, $37,38]$. Other creative works include the research on joint ordering and pricing decisions considering repeat-purchase based on the Bass model [39], retailer's ordering and pricing decisions of responding to the supplier's temporary price discounts [40], ordering and pricing model considering transshipment between two independent retailers [41], and retailer's joint ordering, pricing and advertising decisions [42].

These studies examine retailer's integrated ordering and pricing policies with different model settings. However, a capital-constrained retailer case is not observed in this stream of research. The current paper introduces the capital constraint into the "integrated ordering and pricing decision" problem and investigates retailer's decisions on ordering, pricing, and financing simultaneously.

2.3. Most Related Works and the Differences. Our paper is most related to the works of Petruzzi and Dada [13] and Li et al. [2]. Petruzzi and Dada [13] study how demand uncertainty affects retailer's pricing policy, but the effect of demand uncertainty on ordering policy is not analyzed. However, with a more general model setting, this paper gives an insight into the effects of demand uncertainty on retailer's ordering and pricing policies. Li et al. [2] study retailer's optimal ordering and pricing policies with product returns. In their paper, the retailer is assumed to be with sufficient capital to support its purchase decision, which is a conventional assumption in the "integrated ordering and pricing decisions" literature. However, the current paper studies retailer's integrated decisions on ordering and pricing in the presence of capital constraint, presents how capital constraint affects retailer's integrated ordering and pricing policies, and reveals how these effects influenced by different levels of demand uncertainty.

\section{Problem Description and Assumptions}

This paper considers a supply chain comprising one manufacturer and one retailer. The retailer purchases single seasonal products from the manufacturer before the selling season and then sells them to the customers. The market demand is randomly price-dependent and is formulated as the following linear form: $D(p, \varepsilon)=a-b p+\varepsilon$, where $\varepsilon \in[-A, A]$ is a random term with a uniform distribution whose PDF and CDF are $f(\varepsilon)$ and $F(\varepsilon)$, respectively, and $a, b$, and $A$ are all positive $[2,13,34]$. (Normally, $\varepsilon \in[A, B]$ is adopted in related literature. Here, we adopt $\varepsilon \in[-A, A]$ to reduce the amount of parameters, meanwhile, measuring the demand uncertainty level by the absolute value of $A$ which represents the range of the random fluctuation.) The retailer is likely to face two different kinds of financial statuses, that is, wellfunded and capital constraint. For convenience, a capitalconstrained retailer's internal capital level is normalized to zero without loss of generality $[11,12]$, and it can borrow from external banks at interest rate $r(0 \leq r \leq 1)$. With risk neutral assumption, a well-funded retailer's objective is to determine optimal order quantity and selling price to maximize expected profit, while a capital-constrained retailer should firstly make a financing decision and then make the ordering and pricing decisions. A rational retailer should set a selling price larger than the wholesale price announced by the manufacturer, that is, $p>w$. Furthermore, salvage value of leftovers and penalty cost of shortages are all assumed to be zero $[6,11,12]$. The main model notations are summarized in the Notations. Two crucial assumptions are made as follows.

Assumption 1. $a-w b-A>0$, which means that the market demand is always positive supposing the product is sold at wholesale price $w$. A similar assumption is made by Li et al. [2] to ensure market size $a$ is not too small.

Assumption 2. $A \leq w b$, which means that random term $\varepsilon$ alone cannot bring a positive demand even though the product is sold at wholesale price $w$. It must be pointed out that this assumption is made to ensure the demand uncertainty level is not too high and it is critical for yielding regular conclusions in this paper. Towards the high demand uncertainty case where $A>w b$, results will be more irregular and cannot be derived by strict mathematical proofs; hence it is further studied using numerical experiments in Section 7.

This paper aims to reveal the impacts of demand uncertainty and capital constraint on retailer's integrated ordering and pricing decisions. Three models are established. M0 is a riskless model where market demand is certain with the random term $\varepsilon$ fixed at its mean value. M1 is an uncertainty model where the random term $\varepsilon$ follows uniform distribution as introduced. M2 is an uncertainty-underfunded model where capital constraint is considered on the basis of M1. Through comparing optimal solutions in models M0 and M1, the impacts of demand uncertainty on retailer's optimal ordering and pricing policies can be revealed. Similarly, the impacts of capital constraint on retailer's optimal decisions are investigated by comparing the optimal solutions in models M1 and M2. All these impacts are examined under a low demand uncertainty scenario (i.e., $A \leq w b$ ) and a high demand uncertainty scenario (i.e., $A>w b$ ), respectively, and then the differences of the conclusions will be pointed out.

\section{Model Formulations and Solutions}

4.1. Model M0. In riskless model M0, random term $\varepsilon$ equals its mean value zero; thus M0 is a deterministic model and the market demand is $D(p)=a-b p$. In this model, selling price $p$ is the unique decision variable and the optimization problem is described as

$$
\max _{p} \pi_{\mathrm{M} 0}=(p-w)(a-b p) .
$$

The optimal selling price can be solved as

$$
p^{0}=\frac{a+w b}{2 b} .
$$


Then, the optimal order quantity can be determined as

$$
Q^{0}=\frac{a-w b}{2} .
$$

4.2. Model M1. In uncertainty model M1, random term $\varepsilon \in$ $[-A, A]$ follows uniform distribution. The retailer's objective is to determine the optimal order quantity $Q^{*}$ and optimal selling price $p^{*}$ to maximize expected profit. So the problem is formulated as follows:

$$
\max _{\mathrm{Q}, p} \pi_{\mathrm{M} 1}=p E \min (\mathrm{Q} \wedge D)-w \mathrm{Q} .
$$

Based on $\min (Q \wedge D)=Q-E(Q-D)^{+}$, where $E(Q-$ $D)^{+}=\max (Q-D, 0),(4)$ can be converted into the following formulation:

$$
\max _{Q, p} \pi_{\mathrm{M} 1}=(p-w) Q-p E(Q-D)^{+} .
$$

Define a substitution variable $z$ named stocking factor $[2,13]: z=Q-(a-b p)$, where $z \in[-A, A]$. If realized value of random term $\varepsilon$ is larger than $z$, then market demand exceeds order quantity and shortages occur. Otherwise, market demand is smaller than order quantity and leftovers occur. Then the problem of determining optimal quantity $Q^{*}$ and price $p^{*}$ is converted into the problem of determining optimal stocking factor $z^{*}$ and price $p^{*}$, and (5) can be further transformed into

$$
\max _{z, p} \pi_{\mathrm{M} 1}=(p-w)(z+a-b p)-p \Delta(z)
$$

where $\Delta(z)=\int_{-A}^{z}(z-\varepsilon) f(\varepsilon) d \varepsilon$ measures the expected amount of the leftovers. The second-order derivative of $\pi_{\mathrm{M} 1}$ with respect to $p$ can be obtained as follows:

$$
\frac{\partial^{2} \pi_{\mathrm{M} 1}}{\partial p^{2}}=-2 b .
$$

Obviously, (7) is strictly negative; thus $\pi_{\mathrm{M} 1}$ is always concave in $p$ for any given $z$. Therefore, a two-step optimization method can be used to solve the problem. Firstly, supposing $z$ is given, the unique optimal $p^{*}(z)$ can be obtained from the first-order derivative of $\pi_{\mathrm{M} 1}$ concerning $p$. Substituting $p^{*}(z)$ into (6), then the objective function will contain only one decision variable $z$. Once the optimal stocking factor $z^{*}$ is solved, the optimal price can be obtained as $p^{*}\left(z^{*}\right)$, and the optimal order quantity will be determined by $Q^{*}=$ $a-b p^{*}\left(z^{*}\right)+z^{*}$.

Theorem 3. In uncertainty model M1, the optimal stocking factor $z^{*}$ is uniquely determined by

$$
F\left(z^{*}\right)=\frac{H\left(z^{*}\right)-w b}{H\left(z^{*}\right)+w b},
$$

the optimal price $p^{*}$ is determined by

$$
p^{*}\left(z^{*}\right)=\frac{H\left(z^{*}\right)+w b}{2 b},
$$

and the optimal order quantity $Q^{*}$ is thus obtained as

$$
Q^{*}=z^{*}+a-b p^{*}\left(z^{*}\right)
$$

where $H\left(z^{*}\right)=a+z^{*}-\Delta\left(z^{*}\right)$ and $\Delta\left(z^{*}\right)=\int_{-A}^{z^{*}}\left(z^{*}-\varepsilon\right) f(\varepsilon) d \varepsilon$.

Proof. See the Appendix.

The retailer's optimal expected profit can be obtained by substituting $p^{*}$ and $Q^{*}$ into (5) or by substituting $p^{*}$ and $z^{*}$ into (6).

4.3. Model M2. In uncertainty-underfunded model M2, aside from demand uncertainty, the retailer is faced with capital constraint. Following the convention in existing "capitalconstrained newsvendor" literature, the retailer's internal capital endowment is normalized to zero without loss of generality $[11,12]$. The retailer has access to financing from external banks at loan interest rate $r$, which is exogenously given, and $r \in[0,1]$. The retailer should first make a decision on whether to opt for financing or not and then determine the optimal order quantity $Q^{* *}$ (i.e., equivalent to the decision on the optimal financing amount $B^{*}$ ) and the optimal selling price $p^{* *}$. At the end of the selling season, the retailer repays the loan with the sales revenue. The optimization problem can be described as follows:

$$
\max _{Q, p} \quad \pi_{\mathrm{M} 2}=p E \min (Q \wedge D)-w(1+r) Q
$$

Equation (11) can be converted into the following formulation:

$$
\max _{Q, p} \pi_{\mathrm{M} 2}=(p-w(1+r)) Q-p E(Q-D)^{+} .
$$

Then, by applying the same stocking factor method presented in Section 4.2, (12) can be further transformed as

$$
\max _{z, p} \pi_{\mathrm{M} 2}=(p-w(1+r))(z+a-b p)-p \Delta(z),
$$

where $\Delta(z)=\int_{-A}^{z}(z-\varepsilon) f(\varepsilon) d \varepsilon$. For any given $z, \pi_{\mathrm{M} 2}$ is also concave in $p$. So the same two-step optimization method presented in Section 4.2 can be applied to solve (13). Then, Theorem 4 is concluded.

Theorem 4. In uncertainty-underfunded model M2, the following happens.

(a) If market size a satisfies a $>A+w b(1+r)$, the optimal stocking factor $z^{* *}$ is uniquely determined by

$$
F\left(z^{* *}\right)=\frac{H\left(z^{* *}\right)-w b(1+r)}{H\left(z^{* *}\right)+w b(1+r)},
$$

the optimal price $p^{* *}$ is determined by

$$
p^{* *}\left(z^{* *}\right)=\frac{H\left(z^{* *}\right)+w b(1+r)}{2 b},
$$

and the optimal order quantity $Q^{* *}$ is thus obtained as

$$
Q^{* *}=z^{* *}+a-b p^{* *}\left(z^{* *}\right)
$$


where $H\left(z^{* *}\right)=a+z^{* *}-\Delta\left(z^{* *}\right)$ and $\Delta\left(z^{* *}\right)=\int_{-A}^{z^{* *}}\left(z^{* *}-\right.$ e) $f(\varepsilon) d \varepsilon$.

(b) If market size a satisfies $A+w b<a \leq A+w b(1+r)$, the retailer will not borrow capital to order any quantity.

Proof. See the Appendix.

In the case $a>A+w b(1+r)$, the retailer's optimal expected profit can be obtained by substituting $p^{* *}$ and $Q^{* *}$ into (12) or by substituting $p^{* *}$ and $z^{* *}$ into (13), and the optimal borrowing amount is $B^{*}=w Q^{* *}$. In the case $A+$ $w b<a \leq A+w b(1+r)$, the retailer's optimal borrowing amount and expected profit are both zero.

\section{Model Comparative Analyses}

In this section, comparative analyses of optimal solutions in three models will be carried out to reveal how demand uncertainty and capital constraint affect retailer's optimal ordering and pricing policies towards seasonal products.

5.1. Model MO versus Model M1. From (2) and (3), the optimal solutions of model M0 are intuitional. Based on (8) in Theorem 3, the following properties concerning optimal stocking factor $z^{*}$ in model M1 can be concluded.

Proposition 5. In model M1,

(a) the optimal stocking factor $z^{*}$ is strictly increasing in the market size $a$, that is, $\partial z^{*} / \partial a>0$,

(b) $\lim _{a \rightarrow w b+A} z^{*}=-A$ and $\lim _{a \rightarrow+\infty} z^{*}=A$.

Proof. See the Appendix.

Proposition 5 means that when other parameters are given, the optimal stocking factor $z^{*}$ in model M1 is determined by the market size $a$. There exists a one-toone correspondence relationship between $z^{*}$ and $a$. Based on Proposition 5, the following proposition can be further obtained.

Proposition 6. In model M1, the optimal order quantity $Q^{*}$ is strictly increasing in the market size $a$, that is, $\partial Q^{*} / \partial a>0$, and $\lim _{a \rightarrow w b+A} Q^{*}=0$.

Proof. See the Appendix.

Proposition 6 reveals a one-to-one correspondence relationship between $Q^{*}$ and $a$. From (3), it is clear that the optimal order quantity $Q^{0}$ in riskless model M0 is also increasing in $a$. Then, $Q^{*}$ and $Q^{0}$ can be compared based on the conclusions in Propositions 5 and 6. The optimal prices in models M0 and M1 are compared as well, and all the results are summarized in Theorem 7.

Theorem 7. (a) There always exists a critical value a greater than $A+w b$, and when market size $a$ is more than $\widetilde{a}$, the optimal order quantity in model M1 will be larger than that in model M0, that is, $Q^{*}>Q^{0}$. Otherwise, when a is less than $\tilde{a}, Q^{*}<$
$Q^{0}$ holds. Further, $\tilde{a}$ is uniquely determined by the following equation set where $z$ satisfies $-A \leq z \leq A$

$$
\begin{aligned}
& z^{2}+A^{2}+6 A z=0 \\
& z^{3}-3 A z^{2}+\left(3 A^{2}-4 A \widetilde{a}-4 A w b\right) z+4 A^{2}(\widetilde{a}-3 w b) \\
& \quad-A^{3}=0
\end{aligned}
$$

(b) The optimal price in model M1 is no more than that in model Mo, that is, $p^{*} \leq p^{0}$, and the case $p^{*}=p^{0}$ occurs only when market size a approaches infinity.

Proof. See the Appendix.

Theorem 7 shows that when demand uncertainty level is relatively low (i.e., $A \leq w b$ ), the retailer faced with demand uncertainty always sets a lower price than the riskless retailer. However, its order quantity may be smaller or larger than the riskless retailer's which depends on the level of market size. In summary, when market size is relatively small, the retailer faced with demand uncertainty tends to adopt a "lower price and quantity" policy to stimulate the market demand as well as control the expected leftovers to wrestle with the demand uncertainty. But when market size is relatively large, it will adopt a "lower price but larger quantity" policy to deal with the demand uncertainty.

5.2. Model M1 versus Model M2. When market size is extremely small, that is, $A+w b<a \leq A+w b(1+r)$, the optimal order quantity in model M2 is zero; thus pricing is meaningless. So, comparative analyses between the optimal solutions in models M1 and M2 are performed only under the case of $a>A+w b(1+r)$ which is the most majority of the situation.

It is obvious that, aside from the existing parameters in model M1, the optimal order quantity and selling price in model M2 are also affected by loan interest rate $r$. Based on Theorem 4, the following proposition concerning the optimal stocking factor $z^{* *}$ and loan interest rate $r$ can be concluded.

Proposition 8. In model M2, the optimal stocking factor $z^{* *}$ is strictly decreasing in the loan interest rate $r$, that is, $\partial z^{* *} / \partial r<$ 0 .

Proof. See the Appendix.

Based on Proposition 8, the optimal order quantities and selling prices in models M1 and M2 can be compared, and the results are summarized in Theorem 9.

Theorem 9. When market size satisfies $a>A+w b(1+r)$,

(a) the optimal order quantity in model M2 is no more than that in model M1, that is, $Q^{* *} \leq Q^{*}$,

(b) the optimal price in model M2 is no less than that in model M1, that is, $p^{* *} \geq p^{*}$.

Proof. See the Appendix. 
Theorem 9 reveals that when demand uncertainty level is relatively low (i.e., $A \leq w b$ ), the capital-constrained retailer tends to adopt a "higher price but smaller quantity" policy comparing with the well-funded one. The rationale can be inferred as follows: the loan interest rate causes the increase of unit purchase cost, which leads to the increase of the selling price. Then, a higher price leads to the decrease of market demand, so a smaller quantity is necessary to control the expected leftovers.

Obviously, the same conclusions can be obtained in deterministic demand models by replacing $w(1+r)$ for $w$ in (2) and (3) and then compared with (2) and (3). However, it should be noted that the optimal order quantity and selling price are all linear with loan interest rate under deterministic demand models, but they are all nonlinear with loan interest rate under uncertain demand models. More importantly, when demand uncertainty level is relatively high (i.e., $A>w b$ ), the conclusions in Theorem 9 will not be always established, which will be introduced in Section 7. Results show that the capital-constrained retailer is likely to set a lower price than the well-funded one in some special situations, which is opposite to the conclusion in Theorem 9(b).

\section{Numerical Analyses}

In this paper, models M1 and M2 are both stochastic, and the optimal solutions are all embodied in implicit functions which are not intuitional. Numerical analyses in this section will contribute to a better understanding of the conclusions with two main objectives: (1) validating the theoretic results obtained in Section 5 and (2) comparing the optimal profits in three models.

6.1. Experimental Parameters. To validate the results obtained in Section 5.1, the following parameters are used: $A=$ $5, w=3, b=2$, which satisfies Assumption 2 (i.e., $A \leq w b$ ). Then, in order to validate conclusions obtained in Section 5.2, the market size $a$ should be fixed at a certain value that satisfies $a>A+w b(1+r)$ for any possible value of $r \epsilon$ $[0,1]$; thus $a=50$ is chosen to meet this condition. Finally, expected profits in three models are compared by assuming loan interest rate $r=0.1$.

6.2. Comparisons of Optimal Solutions. Figure 1 shows the change of stocking factor $z^{*}$ with regard to market size $a$ in model M1. It can be observed that as market size increases from its lower bound $w b+A$ (i.e., 11) to infinity, the optimal stocking factor will increase from $-A$ to $A$ (i.e., from -5 to 5 ), which verifies Proposition 5.

Figures 2 and 3 present the relations between the optimal solutions in models M0 and M1. In Figure 2, when market size is smaller than a critical value which is approximately 16.2 (i.e., the abscissa of intersection of the two lines), the optimal order quantity in model M1 will be smaller than that in model M0. Otherwise, the optimal order quantity in model M1 will be larger than that in model M0. From Figure 3, it can be observed that the optimal price in model M1 is always less than that in model M0, and the difference between the two

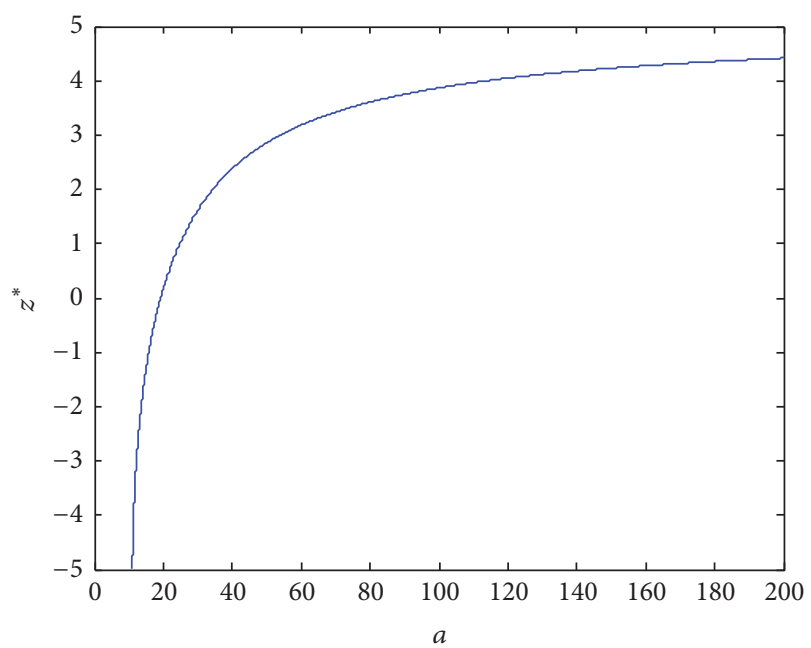

FIGURE 1: Stocking factor with market size varying (model M1).

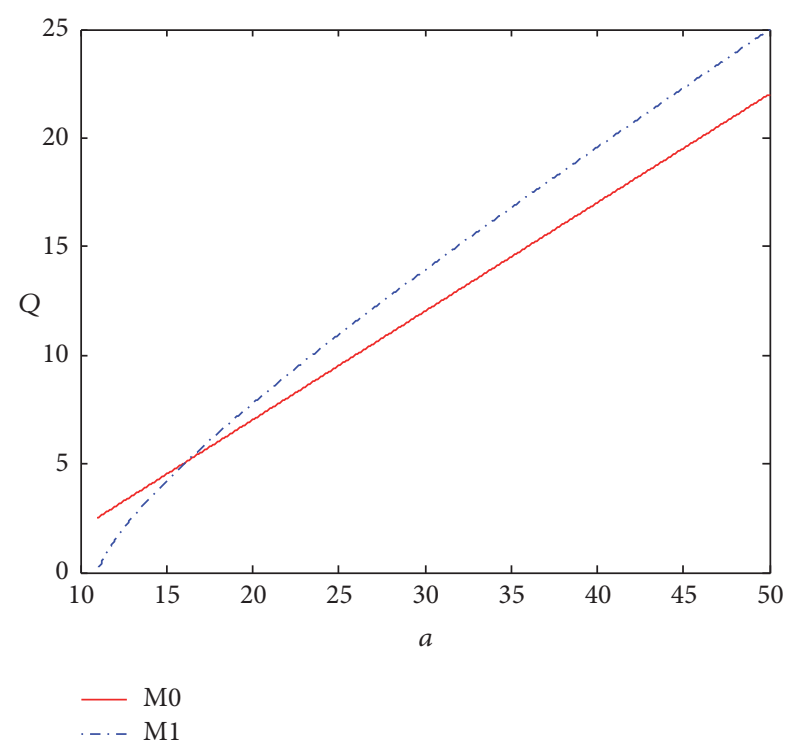

Figure 2: Optimal order quantity comparison in models M0 and M1.

optimal prices will gradually decrease to zero as market size increases to infinity. The above simulation results support the conclusions of Theorem 7.

Figure 4 shows the change of stocking factor $z^{* *}$ with regard to loan interest rate $r$ in model M2. Obviously, the optimal stocking factor is decreasing in loan interest rate in model M2, which verifies Proposition 8.

Figures 5 and 6 present the relations between the optimal solutions in models M1 and M2. Based on Theorem 3, the optimal solutions in model M1 are independent of loan interest rate, so the optimal order quantity and price of model $\mathrm{M} 1$ are all horizontal lines as loan interest rate increases from zero to one (see the dot-dash lines in Figures 5 and 6). The simulation results show that the optimal order quantity in model M2 is equal to or less than that in model M1 while the optimal price in model M2 is equal to or more than that 


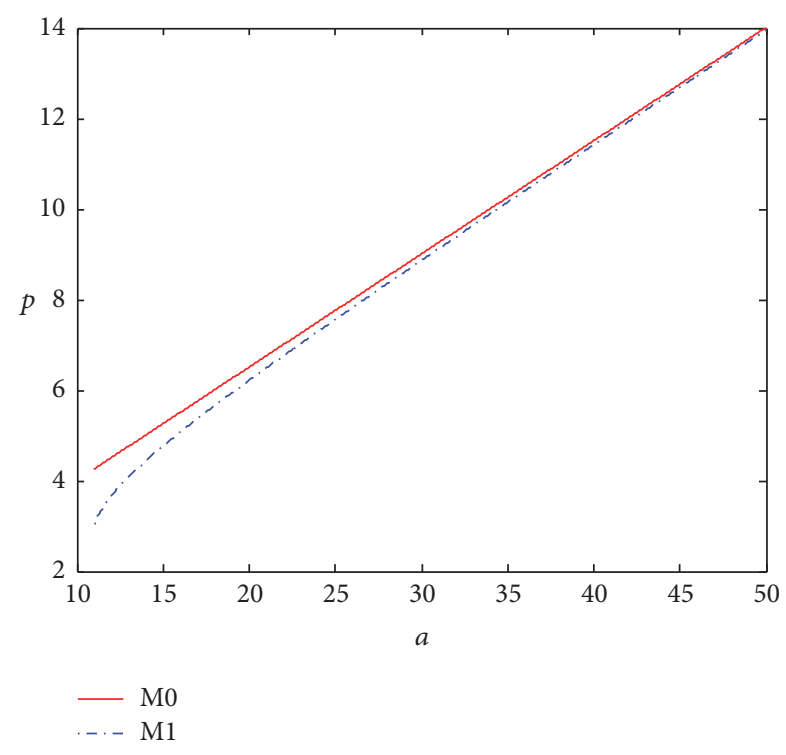

FIGURE 3: Optimal price comparison in models M0 and M1.

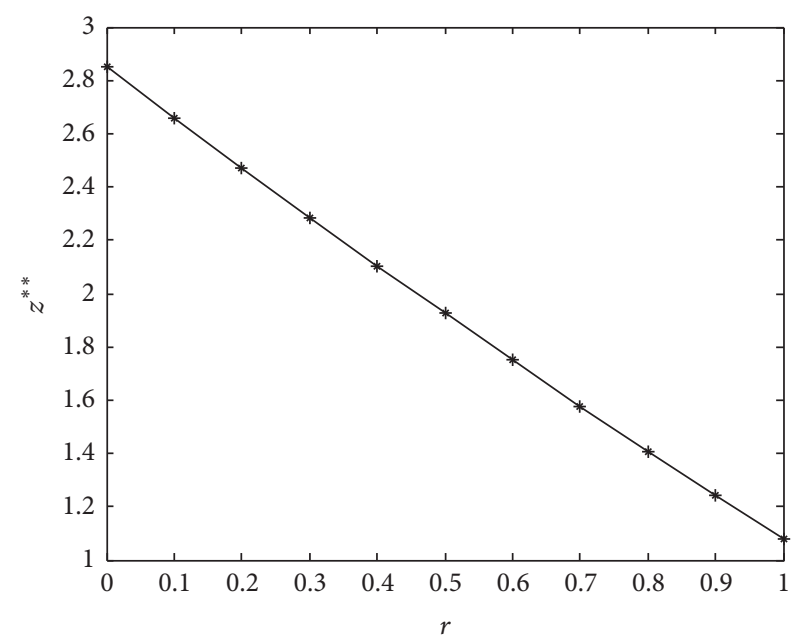

FIGURE 4: Stocking factor with loan interest rate varying (model M2).

in model M1, which are consistent with the conclusions in Theorem 9. Moreover, it can be observed that the equivalent cases occur only when loan interest rate equals zero, and as loan interest rate rises, the difference between the optimal solutions in models M1 and M2 will be enlarged. It should also be noted that the optimal solutions in model M2 are all nonlinear with the loan interest rate, even though the results in our numerical simulations look like linear (see the starsolid lines in Figures 5 and 6).

6.3. Comparison of Expected Profits. In this subsection, comparison of expected profits in three models is performed and the result is shown in Figure 7 . It can be found that expected profit in riskless model M0 is the highest, followed by uncertainty model M1, and expected profit in uncertaintyunderfunded model M2 is the lowest. Furthermore, this

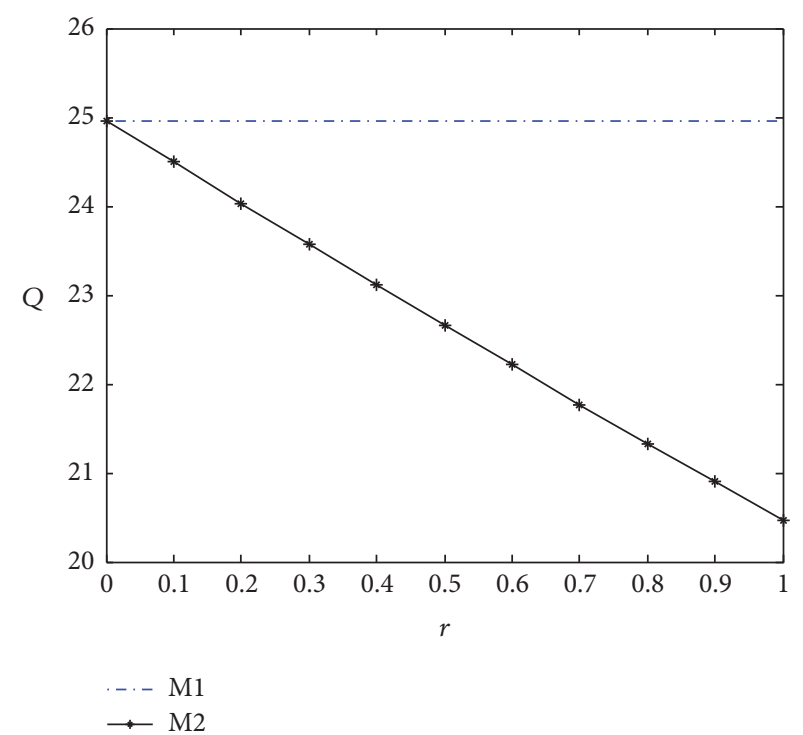

FIGURE 5: Optimal order quantity comparison in models M1 and M2.

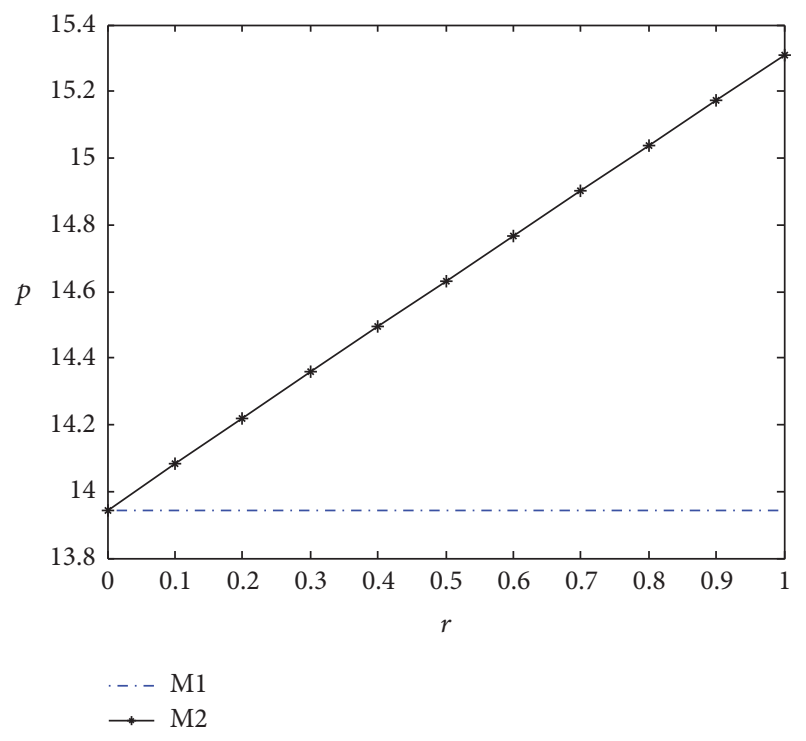

FIGURE 6: Optimal price comparison in models M1 and M2.

quantitative relation is independent of market size. So, both demand uncertainty and capital constraint can be regarded as obstacles for the retailer to overcome, which lead to some losses of efficiency.

\section{Extension for the Case $A>w b$}

When demand uncertainty level is relatively low, that is, $A \leq w b$, some regular results are obtained as shown in Theorems 7 and 9. However, when demand uncertainty level is relatively high, that is, $A>w b$, theoretic results cannot be derived through strict mathematical proofs. In this section, the case $A>w b$ is further studied with the aid of numerical 
TABLe 1: Applicability of conclusions in Theorems 7 and 9 under the case of $A>w b$.

\begin{tabular}{lcccc}
\hline$A$ & Theorem 7(a) & Theorem 7(b) & Theorem 9(a) & Theorem 9(b) \\
\hline $6.00 \sim 8.00$ & $\sqrt{ }$ & $\sqrt{ }$ & $\sqrt{ }$ & $\sqrt{ }$ \\
$8.00 \sim 12.92$ & $\sqrt{ }$ & $\sqrt{ }$ & $\sqrt{ }$ & $\times$ \\
$12.92 \sim 32.00$ & $\times$ & $\sqrt{ }$ & $\sqrt{ }$ & $\times$ \\
$\geq 32.00$ & $\times$ & $\sqrt{ }$ & $\sqrt{ }$ \\
\hline
\end{tabular}

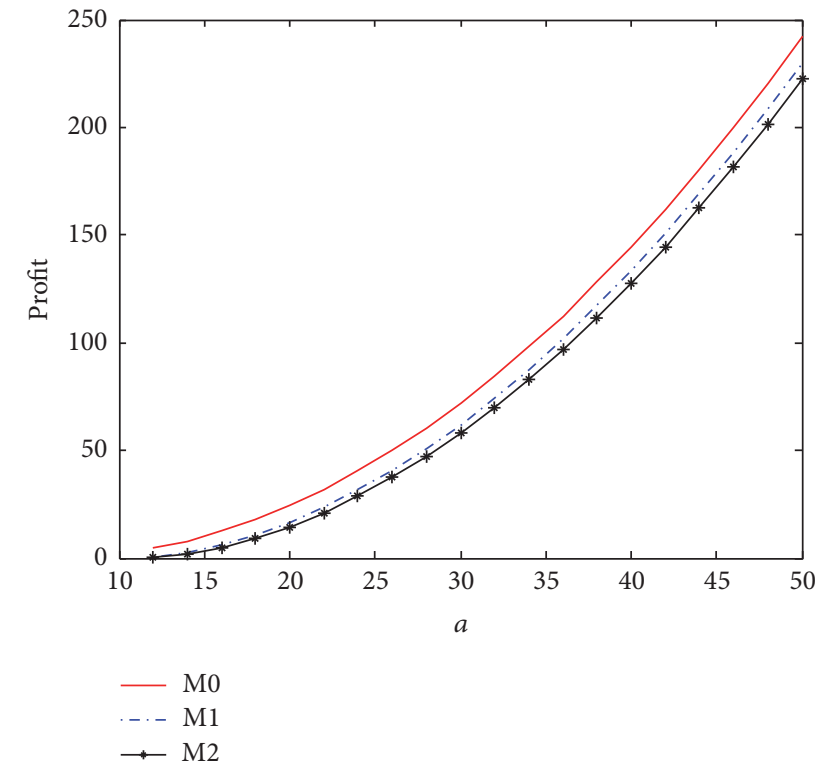

FIgURE 7: Optimal expected profit comparison in models M0, M1, and $\mathrm{M} 2$.

experiments. Consistent with Section $6, w=3, b=2$ are used.

Under the high demand uncertainty case of $A>w b$, Table 1 shows the applicability of conclusions in Theorems 7 and 9. Results are more intricate and irregular, which are summarized in Observation 10.

Observation 10. In the high demand uncertainty case, that is, $A>w b$, the following happen.

(a) Conclusions in Theorems 7(b) and 9(a) are all applicable.

(b) Conclusions in Theorem 7(a) are applicable only when demand uncertainty level is less than a critical value (i.e., approximately 12.92 in our example).

(c) Conclusions in Theorem 9(b) are inapplicable only when demand uncertainty level falls within a specific interval (i.e., approximately 8.00 32.00 in our example).

The inapplicable cases in Table 1 are further explained as follows. For Theorem 7(a), when demand uncertainty level is high enough (i.e., higher than 12.92), the optimal order quantity in model M1 will be always larger than that in model M0, which means two lines in Figure 2 will no longer intersect. An example with $A=15$ is shown in Figure 8.

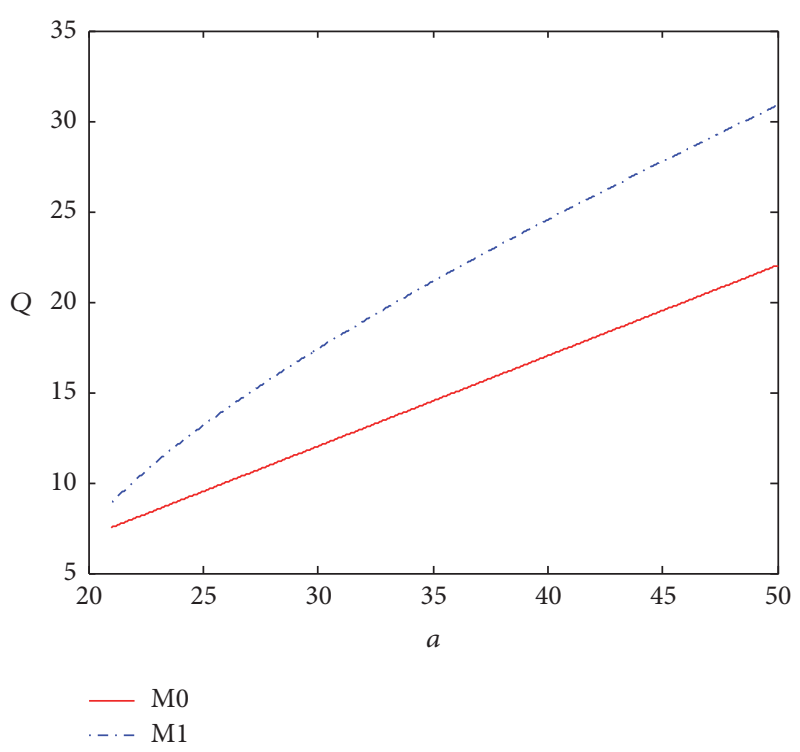

FIGURE 8: Optimal order quantity comparison in models M0 and M1 $(A=15)$.

For Theorem 9(b), when demand uncertainty level is higher than 8.00 but lower than 32.00, a small interval of market size $a$ (see Table 2) incurs the result $p^{* *}<p^{*}$ when assigned with specific values of loan interest rate $r$, which is opposite to the result in Theorem 9(b) with $A \leq w b$. An example is given in Figure 9 with choosing $A=20, a=33$. It can be observed that the case $p^{* *}<p^{*}$ will occur for some higher values of $r$, that is, approximately $0.83 \sim 1.00$.

In summary, the capital-constrained retailer is likely to set a lower price than the well-funded one when demand uncertainty level falls within a subinterval of $A>w b$, which is different from the result obtained in the case $A \leq w b$ where the capital-constrained retailer always sets a higher price than the well-funded one. Therefore, it can be further concluded that the impact of capital constraint on retailer's pricing decision can be influenced by different levels of demand uncertainty.

\section{Conclusions and Future Research}

This paper combines pricing decision into the "capitalconstrained newsvendor" problem and investigates retailer's integrated ordering and pricing policies in the presence of capital constraint. Results show that when market size is extremely small, the retailer will not borrow from the external bank to order any quantity. Otherwise, it will borrow to 
TABLE 2: The interval of market size incurs $p^{* *}<p^{*}$ under $A>w b$.

\begin{tabular}{cccccccc}
\hline$A$ & $6.00-8.00$ & 8.10 & 10.00 & 20.00 & 30.00 & 31.90 & $\geq 32.00$ \\
\hline$a$ & - & $(20.10,20.15)$ & $(22.00,22.83)$ & $(32.00,33.95)$ & $(42.00,42.47)$ & $(43.90,43.92)$ & - \\
\hline
\end{tabular}

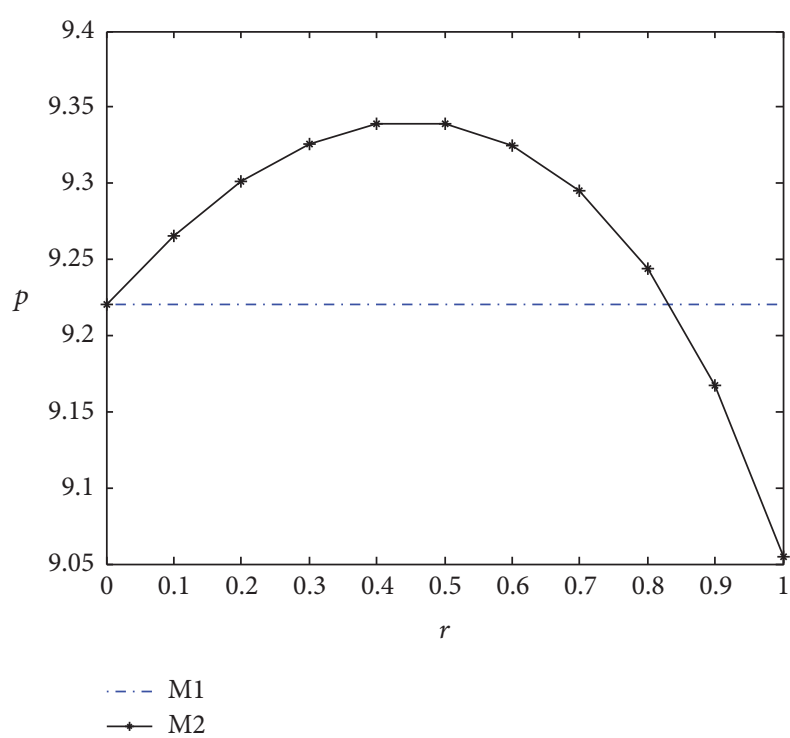

Figure 9: Optimal price comparison in models M1 and M2 $(A=20$, $a=33)$.

order and its optimal order quantity and selling price can be uniquely determined.

Specifically, this paper develops three models (i.e., riskless model, uncertainty model, and uncertainty-underfunded model) to investigate the impacts of demand uncertainty and capital constraint on retailer's integrated ordering and pricing policies under a low and high demand uncertainty scenario, respectively. Theoretical results show that when demand uncertainty level is relatively low (i.e., $A \leq w b$ ), the retailer faced with demand uncertainty always sets a lower price than the riskless one, while its order quantity may be smaller or larger than the riskless retailer's which depends on the level of market size. The retailer with capital constraint always adopts a "higher price but smaller quantity" policy comparing with the well-funded one. However, when demand uncertainty level is relatively high (i.e., $A>w b$ ), numerical results show that the retailer faced with demand uncertainty will always order a larger quantity than the riskless one when demand uncertainty level is high enough (above a critical value), and the retailer with capital constraint is likely to set a lower price than the well-funded one when demand uncertainty level falls within a specific interval. The differences of conclusions in these two scenarios also indicate the impact of capital constraint on retailer's pricing decision can be influenced by different levels of demand uncertainty. What is more, by comparing the optimal profits in three models, it is concluded that both demand uncertainty and capital constraint can be regarded as obstacles for the retailer to tackle, which inevitably lead to some losses of efficiency.
This paper ends with a discussion of the limitations and possible directions. First, the case when demand uncertainty level is relatively high is studied only with numerical experiments due to obstacles of mathematical proofs. Second, some simplification has been made in this paper, such as the supply chain structure, salvage value and shortage cost, and even the retailer's internal capital endowment. Various directions can be explored in future research. More complex scenarios can be considered, such as multichannel for ordering or selling and multiperiod problem. Investigating the ordering and pricing policies of the capital-constrained retailer with considering different internal capital endowments is also meaningful for guiding diverse industrial practices. In addition, other demand formulations (e.g., the multiplicative case) or other financing schemes (e.g., the trade credit financing) can be introduced to do some comparison studies.

\section{Appendix}

Proof of Theorem 3. Based on (7), for any given $z, \pi_{\mathrm{M} 1}$ is concave in $p$, so the unique optimal $p^{*}(z)$ can be obtained by solving $\partial \pi_{\mathrm{M} 1} / \partial p=0$, which is

$$
p^{*}(z)=\frac{a+z-\Delta(z)+w b}{2 b}
$$

Then, substituting $p^{*}(z)$ into (6) and taking the first-order derivative of $\pi_{\mathrm{M} 1}$ with respect to $z$, based on the chain rule, yields

$$
\begin{aligned}
& \frac{d \pi_{\mathrm{M} 1}}{d z}=\frac{\partial \pi_{\mathrm{M} 1}}{\partial z}+\frac{\partial \pi_{\mathrm{M} 1}}{\partial p^{*}(z)} \frac{d p^{*}(z)}{d z} \\
& \quad=\frac{1}{2 b}((a+z-\Delta(z)+w b)(1-F(z))-2 w b) .
\end{aligned}
$$

Letting $G(z)=(a+z-\Delta(z)+w b)(1-F(z))-2 w b$, the second-order derivative of $G(z)$ is

$$
\frac{\partial^{2} G(z)}{\partial z^{2}}=-3 f(z)(1-F(z)) \leq 0
$$

Thus $G(z)$ is concave and unimodal in $z$. Further, since $G(A)=-2 w b<0$ and $G(-A)=a-w b-A>0$ (Assumption 1), there always exists a unique $z^{*} \in[-A, A]$ that satisfies $G\left(z^{*}\right)=0$. Obviously, when $z<z^{*}, d \pi_{\mathrm{M} 1} / d z>$ 0 ; and when $z>z^{*}, d \pi_{\mathrm{M} 1} / d z<0$. By letting (A.2) equal zero, a unique $z^{*}$ that maximizes $\pi_{\mathrm{M} 1}$ can be obtained as shown in (8) where $H\left(z^{*}\right)=a+z^{*}-\Delta\left(z^{*}\right)$. Then, the optimal price $p^{*}\left(z^{*}\right)$ is determined by substituting $z^{*}$ into (A.1), and the optimal order quantity is thus $Q^{*}=a-b p^{*}\left(z^{*}\right)+z^{*}$ based on the definition of stocking factor $z$. 
Proof of Theorem 4. For any given $z, \partial^{2} \pi_{\mathrm{M} 2} / \partial p^{2}=-2 b<0$, so $\pi_{\mathrm{M} 2}$ is also concave in $p$. The unique optimal $p^{* *}(z)$ can be obtained by solving $\partial \pi_{\mathrm{M} 2} / \partial p=0$. Then, substituting $p^{* *}(z)$ into (13) and taking the first-order derivative of $\pi_{\mathrm{M} 2}$ with respect to $z$, based on the chain rule, yields

$$
\begin{aligned}
& \frac{d \pi_{\mathrm{M} 2}}{d z}=\frac{1}{2 b}((a+z-\Delta(z)+w b(1+r))(1-F(z)) \\
& \quad-2 w b(1+r)) .
\end{aligned}
$$

Letting $G(z)=(a+z-\Delta(z)+w b(1+r))(1-F(z))-2 w b(1+r)$, the second-order derivative of $G(z)$ is the same as shown in (A.3), so $G(z)$ is concave and unimodal in $z$. Further, it can be easily calculated that $G(A)=-2 w b(1+r)<0$ and $G(-A)=$ $a-A-w b(1+r)$.
Case (a). When $a>A+w b(1+r), G(-A)>0$, the proof is similar to the proof of Theorem 3.

Case (b). When $A+w b<a \leq A+w b(1+r), G(-A) \leq 0$ in conjunction with $G^{\prime}(-A)=1-f(-A)(a-A+w b(1+r))<$ $1-w b / A-w b r / 2 A<0$ (Assumptions 1 and 2), it can be concluded that $G(z) \leq 0$ over $[-A, A]$; thus $\pi_{\mathrm{M} 2}$ is decreasing in $z$ over $[-A, A]$ and the optimal stocking factor is $z^{* *}=$ $-A$. Then, the optimal selling price and order quantity can be determined as $p^{* *}(-A)=(a-A+w b(1+r)) / 2 b$ and $Q^{* *}=(a-A-w b(1+r)) / 2$, respectively. Since $a \leq A+$ $w b(1+r)$, we have $Q^{* *} \leq 0$. Because the order quantity must be nonnegative, that is, $Q^{* *} \geq 0$, and based on $Q^{* *}=$ $\left(a+z^{* *}+\Delta\left(z^{* *}\right)-w b(1+r)\right) / 2$, larger $Q^{* *}$ requires larger $z^{* *}$, causing a decrease in $\pi_{\mathrm{M} 2}$. Thus, $Q^{* *}=0$ is the optimal decision for Case (b).

Proof of Proposition 5. For part (a), taking the first-order derivative of (8) with respect to $a$ yields

$$
\begin{aligned}
& f\left(z^{*}\right) \frac{\partial z^{*}}{\partial a} \\
& =\frac{\left(1+\partial z^{*} / \partial a-F\left(z^{*}\right)\left(\partial z^{*} / \partial a\right)\right)\left(a+z^{*}-\Delta\left(z^{*}\right)+w b\right)-\left(a+z^{*}-\Delta\left(z^{*}\right)-w b\right)\left(1+\partial z^{*} / \partial a-F\left(z^{*}\right)\left(\partial z^{*} / \partial a\right)\right)}{\left(a+z^{*}-\Delta\left(z^{*}\right)+w b\right)^{2}} .
\end{aligned}
$$

Equation (A.5) can be simplified as

$$
\begin{aligned}
& \left(\frac{f\left(z^{*}\right)\left(a+z^{*}-\Delta\left(z^{*}\right)+w b\right)^{2}}{2 w b}+F\left(z^{*}\right)\right. \\
& -1) \frac{\partial z^{*}}{\partial a}=1 .
\end{aligned}
$$

Letting $L\left(z^{*}\right)=f\left(z^{*}\right)\left(a+z^{*}-\Delta\left(z^{*}\right)+w b\right)^{2} / 2 w b+F\left(z^{*}\right)-1$, taking the first-order derivative of $L\left(z^{*}\right)$ concerning $z^{*}$ yields

$$
\begin{aligned}
& \frac{\partial L\left(z^{*}\right)}{\partial z^{*}} \\
& \quad=\frac{2 f\left(z^{*}\right)\left(a+z^{*}-\Delta\left(z^{*}\right)+w b\right)\left(1-F\left(z^{*}\right)\right)}{2 w b} \\
& \quad+f\left(z^{*}\right) .
\end{aligned}
$$

Since $a+z^{*}-\Delta\left(z^{*}\right)+w b$ is increasing in $z^{*}$ and $z^{*} \in[-A, A]$, the minimum value of $a+z^{*}-\Delta\left(z^{*}\right)+w b$ is $a-A+w b$ which is strictly positive based on Assumption 1. Therefore, (A.7) is strictly positive, which means $L\left(z^{*}\right)$ is increasing in $z^{*}$. When $z^{*}=-A$, based on Assumptions 1 and 2 , the minimum value of $L\left(z^{*}\right)$ is obtained as

$$
\begin{aligned}
L(-A) & =\frac{(a-A+w b)^{2}}{4 A w b}-1>\frac{(2 w b)^{2}}{4 A w b}-1 \\
& =\frac{w b-A}{A} \geq 0 .
\end{aligned}
$$

Until now, it can be concluded that $L\left(z^{*}\right)$ is strictly positive for $z^{*} \in[-A, A]$. Then, based on (A.6), $\partial z^{*} / \partial a>0$ is proved.

For part (b), based on the proof of Theorem 3, it is clear that $G(z)$ is concave and unimodal in $z$ and $G(A)<0$, $G(-A)=a-w b-A>0$. When $a \rightarrow w b+A$, we have $G(-A) \rightarrow 0^{+}$. Two cases should be considered.

Case (1). $-A$ infinitely approaches the smaller root of $G(z)$, when the unique optimal stocking factor $z^{*}$ over $[-A, A]$ will be the larger root of $G(z)$ which is more than $-A$.

Case (2). $-A$ infinitely approaches the larger root of $G(z)$, when $z^{*}$ over $[-A, A]$ will be $-A$.

The sign of the first-order derivative can be used to distinguish the above two cases, because $G^{\prime}(-A)>0$ holds in Case (1), while $G^{\prime}(-A)<0$ holds in Case (2). The first-order derivative of $G(z)$ is as follows:

$$
\begin{aligned}
G^{\prime}(z) & =\frac{\partial G(z)}{\partial z} \\
& =(1-F(z))^{2}-f(z)(a+z-\Delta(z)+w b) .
\end{aligned}
$$

Based on Assumptions 1 and 2, it can be further obtained that

$$
G^{\prime}(-A)=1-\frac{1}{2 A}(a-A+w b)<1-\frac{w b}{A} \leq 0 .
$$

This supports Case (2). Thus, $\lim _{a \rightarrow w b+A} z^{*}=-A$.

Further, when $a \rightarrow+\infty$, using L'Hospitol principle, the right side of (8) equals one. Solving $F\left(z^{*}\right)=1$ yields $z^{*}=$ A. 
Proof of Proposition 6. Based on (9) and (10), the optimal order quantity in model M1 is

$$
Q^{*}=\frac{a+z^{*}+\Delta\left(z^{*}\right)-w b}{2} .
$$

Taking the first-order derivative of $Q^{*}$ with respect to $a$, based on Proposition 5, yields

$$
\begin{aligned}
\frac{\partial Q^{*}}{\partial a} & =\frac{1}{2}\left(1+\left(1+F\left(z^{*}\right)\right) \frac{\partial z^{*}}{\partial a}\right)>0, \\
\lim _{a \rightarrow w b+A} Q^{*} & =\frac{w b+A-A+0-w b}{2}=0 .
\end{aligned}
$$

This completes the proof of Proposition 6.

Proof of Theorem 7. For part (a), define $\Delta Q=Q^{*}-Q^{0}=$ $\left(z^{*}+\Delta\left(z^{*}\right)\right) / 2$. Obviously, $\Delta Q$ is strictly increasing in $z^{*}$. By Proposition $5, z^{*}$ is strictly increasing in $a$; thus $\Delta Q$ is strictly increasing in $a$. Then, $\lim _{a \rightarrow w b+A} \Delta Q=-A / 2<0$ and $\lim _{a \rightarrow+\infty} \Delta Q=A>0$ can be obtained based on Propositions 5 and 6 . So, there always exists a critical value $\widetilde{a}$ more than $A+w b$, when $a<\tilde{a}$ yields $\Delta Q<0$ and when $a>\tilde{a}$ yields $\Delta Q>0$. Further, under the critical value $\widetilde{a}$, unique $z^{*} \in[-A, A]$ is determined by (8) based on Theorem 3 , which can be explicitly described as

$$
\begin{gathered}
z^{* 3}-3 A z^{* 2}+\left(3 A^{2}-4 A \widetilde{a}-4 A w b\right) z^{*} \\
+4 A^{2}(\widetilde{a}-3 w b)-A^{3}=0
\end{gathered}
$$

and $z^{*}$ must simultaneously solve $\Delta Q=\left(z^{*}+\Delta\left(z^{*}\right)\right) / 2=0$, which is equivalent to

$$
z^{* 2}+A^{2}+6 A z^{*}=0
$$

It is easy to verify that (A.14) has only one root over $[-A, A]$; then based on unique $z^{*}$, (A.13) can uniquely determine the value of $\widetilde{a}$. Therefore, the solution of the equation set comprised of (A.13) and (A.14) can determine unique $\tilde{a}$ under the constraint $z^{*} \in[-A, A]$, which is the conclusion of part (a).

For part (b), based on (2) and (9),

$$
p^{*}=p^{0}+\frac{z^{*}-\Delta\left(z^{*}\right)}{2 b}
$$

It is clear that $\partial\left(z^{*}-\Delta\left(z^{*}\right)\right) / \partial z^{*}=1-F\left(z^{*}\right) \geq 0$, so the maximum value of $z^{*}-\Delta\left(z^{*}\right)$ can be obtained by letting $z^{*}=$ $A$, which is zero. Thus $p^{*} \leq p^{0}$ holds. By Proposition 5, the case $z^{*}=A$ occurs only when $a$ approaches infinity.
Proof of Proposition 8. Equation (14) can be rewritten as the following formulation:

$$
w b(1+r)\left(1+F\left(z^{* *}\right)\right)=H\left(z^{* *}\right)\left(1-F\left(z^{* *}\right)\right) .
$$

Taking the first-order derivative of (A.16) with respect to $r$ yields

$$
\begin{aligned}
& w b\left(1+F\left(z^{* *}\right)\right)+w b(1+r) f\left(z^{* *}\right) \frac{\partial z^{* *}}{\partial r} \\
& =\left(1-F\left(z^{* *}\right)\right)^{2} \frac{\partial z^{* *}}{\partial r}-f\left(z^{* *}\right) H\left(z^{* *}\right) \frac{\partial z^{* *}}{\partial r}
\end{aligned}
$$

Further,

$$
\begin{aligned}
& \frac{\partial z^{* *}}{\partial r} \\
& =\frac{w b\left(1+F\left(z^{* *}\right)\right)}{\left(1-F\left(z^{* *}\right)\right)^{2}-f\left(z^{* *}\right) H\left(z^{* *}\right)-w b(1+r) f\left(z^{* *}\right)} .
\end{aligned}
$$

Obviously, the numerator is positive. Letting the denominator be $T\left(z^{* *}\right)$, taking the first-order derivative of $T\left(z^{* *}\right)$ with respect to $z^{* *}$ yields $\partial T\left(z^{* *}\right) / \partial z^{* *}=-3 f\left(z^{* *}\right)\left(1-F\left(z^{* *}\right)\right)$ which is nonpositive. Since $a>A+w b(1+r)$, the maximum value of $T\left(z^{* *}\right)$ is

$$
\begin{aligned}
T(-A) & =\frac{3 A-a-w b(1+r)}{2 A}<\frac{A-w b(1+r)}{A} \\
& \leq 0
\end{aligned}
$$

Hence, $T\left(z^{* *}\right)$ is always negative over $[-A, A]$. Thus, (A.18) is negative, and the proof is completed.

Proof of Theorem 9. For part (a), based on (8) and (14), when $r=0, Q^{* *}=Q^{*}$ holds. Since $r \in[0,1]$ and $Q^{*}$ is independent of $r$, as long as $\partial Q^{* *} / \partial r<0$ is proved, $Q^{* *} \leq Q^{*}$ will be proved. From (15) and (16),

$$
\frac{\partial Q^{* *}}{\partial r}=\frac{1}{2}\left(\left(1+F\left(z^{* *}\right)\right) \frac{\partial z^{* *}}{\partial r}-w b\right) .
$$

$\partial z^{* *} / \partial r<0$ has been proved in Proposition 8, thus yielding $\partial Q^{* *} / \partial r<0$.

For part (b), similar to the proof for part (a), when $r=0$, $p^{* *}=p^{*}$ holds. Hence, as long as $\partial p^{* *} / \partial r \geq 0$ is proved, $p^{* *} \geq p^{*}$ will be automatically proved. From (15), taking the first-order derivative of $p^{* *}$ with respect to $r$ yields

$$
\frac{\partial p^{* *}}{\partial r}=\frac{1}{2 b}\left(\left(1-F\left(z^{* *}\right)\right) \frac{\partial z^{* *}}{\partial r}+w b\right) .
$$

Substituting (A.18) into (A.21) yields

$$
\frac{\partial p^{* *}}{\partial r}=\frac{1}{2 b}\left(\frac{w b\left(1-F^{2}\left(z^{* *}\right)\right)}{\left(1-F\left(z^{* *}\right)\right)^{2}-f\left(z^{* *}\right) H\left(z^{* *}\right)-w b(1+r) f\left(z^{* *}\right)}+w b\right)
$$


Let $R\left(z^{* *}\right)=w b\left(1-F^{2}\left(z^{* *}\right)\right) /\left(\left(1-F\left(z^{* *}\right)\right)^{2}-f\left(z^{* *}\right) H\left(z^{* *}\right)-\right.$ $\left.w b(1+r) f\left(z^{* *}\right)\right)+w b$. To prove $\partial p^{* *} / \partial r \geq 0$ is equivalent to proving $R\left(z^{* *}\right) \geq 0$, which can be simplified as follows:

$$
\begin{aligned}
\left(1-F^{2}\left(z^{* *}\right)\right) \leq & f\left(z^{* *}\right) H\left(z^{* *}\right) \\
& +w b(1+r) f\left(z^{* *}\right) \\
& -\left(1-F\left(z^{* *}\right)\right)^{2}
\end{aligned}
$$

Further, (A.23) can be reduced to

$$
z^{* * 2}-10 A z^{* *}+9 A^{2}-4 A(a+w b(1+r)) \leq 0
$$

Next, (A.24) will be proved to be always true for $z^{* *} \epsilon$ $[-A, A]$. Let $U\left(z^{* *}\right)=z^{* * 2}-10 A z^{* *}+9 A^{2}-4 A(a+w b(1+r))$. It is clear that when $z^{* *}=A, U(A)=-4 A(a+w b(1+r))<0$. Based on Proposition 5, it can be inferred that $z^{* *}=-A$ occurs only when the market size infinitely approaches its lower bound, that is, $a \rightarrow A+w b(1+r)$. Further, $a>A+2 w b$ must hold in order to ensure that $a>A+w b(1+r)$ for any $r \in[0,1]$. Thus, $a \rightarrow A+w b(1+r)$ occurs only when $a \rightarrow A+2 w b$ in conjunction with $r \rightarrow 1$. Therefore,

$$
\begin{aligned}
U(-A) & =20 A^{2}-4 A(A+2 w b+w b(1+1)) \\
& =16 A(A-w b) .
\end{aligned}
$$

Based on Assumption 2, (A.25) is nonpositive. Since $U\left(z^{* *}\right)$ is a quadratic function with convexity, it can be concluded that $U\left(z^{* *}\right) \leq 0$ over $[-A, A]$. Until now, (A.24) has been proved to be always true, ensuring that $\partial p^{* *} / \partial r \geq 0$ holds in (A.22). Theorem 9 is thus proved.

\section{Notations}

$\begin{array}{ll}a: & \begin{array}{l}\text { Demand intercept which represents } \\ \text { market size }\end{array} \\ b: & \begin{array}{l}\text { Price coefficient which represents slope of } \\ \text { the linear demand curve }\end{array} \\ \varepsilon: & \text { Random term in demand function } \\ -A, A: & \text { Lower and upper bound of } \varepsilon \text {, respectively, } \\ & \text { whose absolute values measure the level of } \\ & \text { demand uncertainty } \\ f(\varepsilon), F(\varepsilon): & \text { PDF and CDF of } \varepsilon, \text { respectively } \\ r: & \text { Loan interest rate } \\ D: & \text { Market demand } \\ i: & \text { Index taking a value among } 0,1, \text { and } 2 \\ \pi_{\mathrm{M} i}: & \text { Retailer's profit function in model Mi } i \\ w: & \text { Unit wholesale price announced by the } \\ & \text { manufacturer } \\ p: & \text { Unit selling price set by the retailer } \\ Q: & \text { Order quantity of the retailer }\end{array}$

$Q^{0}, p^{0}: \quad$ Retailer's optimal order quantity and selling price in model M0, respectively

$Q^{*}, p^{*}: \quad$ Retailer's optimal order quantity and selling price in model M1, respectively

$Q^{* *}, p^{* *}:$ Retailer's optimal order quantity and selling price in model M2, respectively

$z$ : $\quad$ Stocking factor whose definition will be

explained in the ensuing chapters

$z^{*}, z^{* *}: \quad$ Optimal stocking factor in models M1 and M2, respectively.

\section{Competing Interests}

The authors declare that there is no conflict of interests regarding the publication of this paper.

\section{Acknowledgments}

This research is supported by the National Natural Science Foundation of China (Grant nos. 71473193, 71403031) and Fundamental Research Funds for the Central Universities of China (Grant no. skz2014010).

\section{References}

[1] F. Hu, C.-C. Lim, and Z. Lu, "Optimal production and procurement decisions in a supply chain with an option contract and partial backordering under uncertainties," Applied Mathematics and Computation, vol. 232, no. 1, pp. 1225-1234, 2014.

[2] Y. Li, C. Wei, and X. Cai, "Optimal pricing and order policies with $\mathrm{B} 2 \mathrm{~B}$ product returns for fashion products," International Journal of Production Economics, vol. 135, no. 2, pp. 637-646, 2012.

[3] X. Chen, Z. Pang, and L. Pan, "Coordinating inventory control and pricing strategies for perishable products," Operations Research, vol. 62, no. 2, pp. 284-300, 2014.

[4] H. Fu, B. Dan, and X. Sun, "Joint optimal pricing and ordering decisions for seasonal products with weather-sensitive demand," Discrete Dynamics in Nature and Society, vol. 2014, Article ID 105098, 8 pages, 2014.

[5] H. Sun, "The research on financing problems of PRC's SMEs," International Business and Management, vol. 10, no. 2, pp. 6974, 2015.

[6] P. Kouvelis and W. Zhao, "Financing the newsvendor: supplier vs. bank, and the structure of optimal trade credit contracts," Operations Research, vol. 60, no. 3, pp. 566-580, 2012.

[7] M. Dada and Q. Hu, "Financing newsvendor inventory," Operations Research Letters, vol. 36, no. 5, pp. 569-573, 2008.

[8] Y. Feng, Y. Mu, B. Hu, and A. Kumar, "Commodity options purchasing and credit financing under capital constraint," International Journal of Production Economics, vol. 153, no. 1, pp. 230-237, 2014.

[9] X. Yan and Y. Wang, "A newsvendor model with capital constraint and demand forecast update," International Journal of Production Research, vol. 52, no. 17, pp. 5021-5040, 2014.

[10] B. Jing, X. Chen, and G. G. Cai, "Equilibrium financing in a distribution channel with capital constraint," Production and Operations Management, vol. 21, no. 6, pp. 1090-1101, 2012.

[11] B. Jing and A. Seidmann, "Finance sourcing in a supply chain," Decision Support Systems, vol. 58, no. 1, pp. 15-20, 2014. 
[12] X. Chen, "A model of trade credit in a capital-constrained distribution channel," International Journal of Production Economics, vol. 159, no. 1, pp. 347-357, 2015.

[13] N. C. Petruzzi and M. Dada, "Pricing and the newsvendor problem: a review with extensions," Operations Research, vol. 47, no. 2, pp. 183-194, 1999.

[14] L. Zhao and A. Huchzermeier, "Operations-finance interface models: a literature review and framework," European Journal of Operational Research, vol. 244, no. 3, pp. 905-917, 2015.

[15] X. Xu and J. R. Birge, "Joint production and financing decisions: modelling and analysis," Working Paper, Graduate School of Business, University of Chicago, 2004.

[16] J. A. Buzacott and R. Q. Zhang, "Inventory management with asset-based financing," Management Science, vol. 50, no. 9, pp. 1274-1292, 2004

[17] P. Kouvelis and W. Zhao, "The newsvendor problem and priceonly contract when bankruptcy costs exist," Production and Operations Management, vol. 20, no. 6, pp. 921-936, 2011.

[18] Z. Molamohamadi, N. Ismail, Z. Leman, and N. Zulkifli, "Reviewing the literature of inventory models under trade credit contact," Discrete Dynamics in Nature and Society, vol. 2014, Article ID 975425, 19 pages, 2014.

[19] G. G. Cai, X. Chen, and Z. Xiao, "The roles of bank and trade credits: theoretical analysis and empirical evidence," Production and Operations Management, vol. 23, no. 4, pp. 583-598, 2014.

[20] N. Yan, B. Sun, H. Zhang, and C. Liu, "A partial credit guarantee contract in a capital-constrained supply chain: financing equilibrium and coordinating strategy," International Journal of Production Economics, vol. 173, pp. 122-133, 2016.

[21] B. Zhang, D. Wu, L. Liang, and D. L. Olson, "Supply chain loss averse newsboy model with capital constraint," IEEE Transactions on Systems, Man, and Cybernetics: Systems, vol. 46, no. 5, pp. 646-658, 2016.

[22] M. N. Katehakis, B. Melamed, and J. J. Shi, "Cash-flow based dynamic inventory management," Production and Operations Management, vol. 25, no. 9, pp. 1558-1575, 2016.

[23] B. Wang, D.-C. Huang, H. Li, and J.-Y. Ding, "Optimal decisions and financing strategies selection of supply chain with capital constraint," Mathematical Problems in Engineering, vol. 2016, Article ID 6597259, 14 pages, 2016.

[24] Y. Li, T. Chen, and B. Xin, "Optimal financing decisions of two cash-constrained supply chains with complementary products," Sustainability, vol. 8, no. 5, pp. 429-445, 2016.

[25] T. M. Whitin, "Inventory control and price theory," Management Science, vol. 2, no. 1, pp. 61-68, 1955.

[26] E. S. Mills, "Uncertainty and price theory," The Quarterly Journal of Economics, vol. 73, no. 1, pp. 116-130, 1959.

[27] J. A. Van Mieghem and M. Dada, "Price versus production postponement: capacity and competition," Management Science, vol. 45, no. 12, pp. 1631-1649, 1999.

[28] J. Chen and P. C. Bell, "Coordinating a decentralized supply chain with customer returns and price-dependent stochastic demand using a buyback policy," European Journal of Operational Research, vol. 212, no. 2, pp. 293-300, 2011.

[29] M. Xu and Y. Lu, "The effect of supply uncertainty in pricesetting newsvendor models," European Journal of Operational Research, vol. 227, no. 3, pp. 423-433, 2013.

[30] W. Jammernegg and P. Kischka, "The price-setting newsvendor with service and loss constraints," Omega, vol. 41, no. 2, pp. 326335, 2013.
[31] P. Abad, "Determining optimal price and order size for a price setting newsvendor under cycle service level," International Journal of Production Economics, vol. 158, pp. 106-113, 2014.

[32] W. Chung, S. Talluri, and R. Narasimhan, "Optimal pricing and inventory strategies with multiple price markdowns over time," European Journal of Operational Research, vol. 243, no. 1, pp. 130-141, 2015.

[33] J. Shi, G. Zhang, and K. K. Lai, "Optimal ordering and pricing policy with supplier quantity discounts and price-dependent stochastic demand," Optimization, vol. 61, no. 2, pp. 151-162, 2012.

[34] C. Wang and X. Chen, "Optimal ordering policy for a pricesetting newsvendor with option contracts under demand uncertainty," International Journal of Production Research, vol. 53, no. 20, pp. 6279-6293, 2015.

[35] W. Xing, S. Wang, and L. Liu, "Optimal ordering and pricing strategies in the presence of a B2B Spot market," European Journal of Operational Research, vol. 221, no. 1, pp. 87-98, 2012.

[36] D. A. Serel, "Production and pricing policies in dual sourcing supply chains," Transportation Research Part E: Logistics and Transportation Review, vol. 76, pp. 1-12, 2015.

[37] K. Pan, K. K. Lai, L. Liang, and S. C. H. Leung, “Two-period pricing and ordering policy for the dominant retailer in a twoechelon supply chain with demand uncertainty," Omega, vol. 37, no. 4, pp. 919-929, 2009.

[38] H. Li and A. Thorstenson, "A multi-phase algorithm for a joint lot-sizing and pricing problem with stochastic demands," International Journal of Production Research, vol. 52, no. 8, pp. 2345-2362, 2014.

[39] X. Wu and J. Zhang, "Joint ordering and pricing decisions for new repeat-purchase products," Discrete Dynamics in Nature and Society, vol. 2015, Article ID 461959, 8 pages, 2015.

[40] Y. Xia, "Responding to supplier temporary price discounts in a supply chain through ordering and pricing decisions," International Journal of Production Research, vol. 54, no. 7, pp. 1938-1950, 2016.

[41] B. Dan, Q. He, K. Zheng, and R. Liu, "Ordering and pricing model of retailers' preventive transshipment dominated by manufacturer with conditional return," Computers \& Industrial Engineering, vol. 100, no. 1, pp. 24-33, 2016.

[42] B.-B. Cao, Z.-P. Fan, H. Li, and T.-H. You, "Joint inventory, pricing, and advertising decisions with surplus and stockout loss aversions," Discrete Dynamics in Nature and Society, vol. 2016, Article ID 1907680, 14 pages, 2016. 


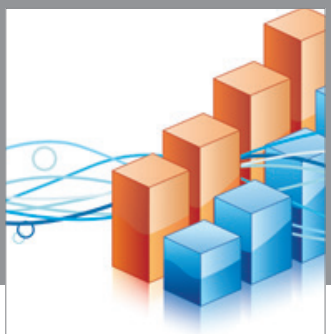

Advances in

Operations Research

vatem alat4

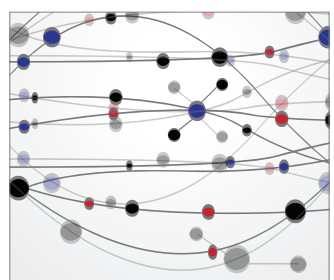

\section{The Scientific} World Journal
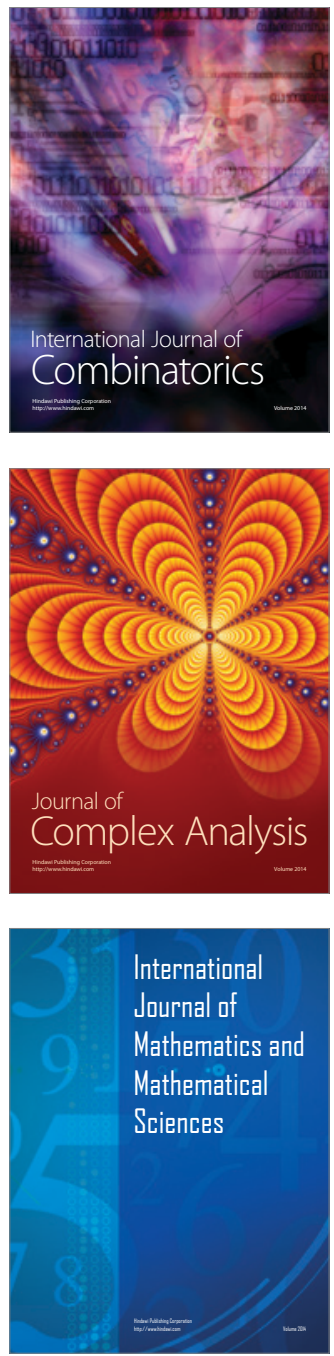
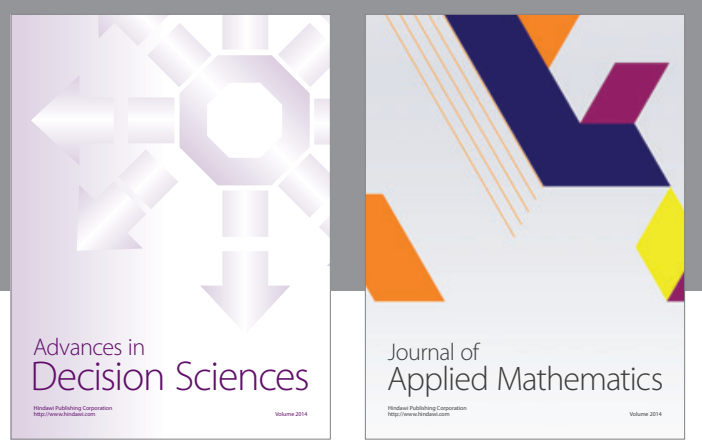

Algebra

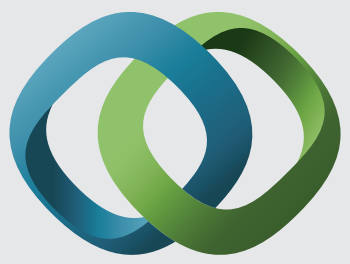

\section{Hindawi}

Submit your manuscripts at

http://www.hindawi.com
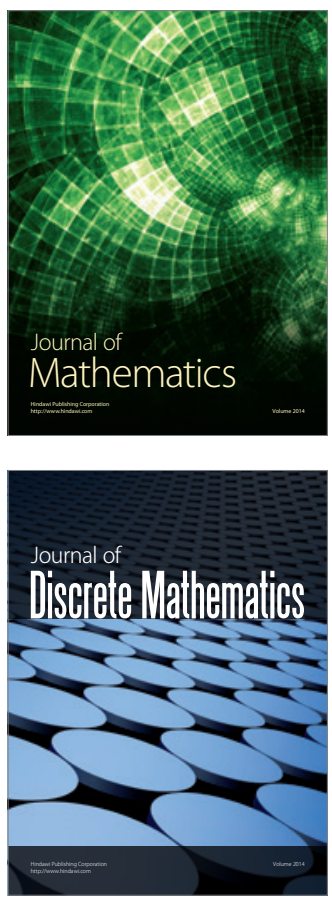

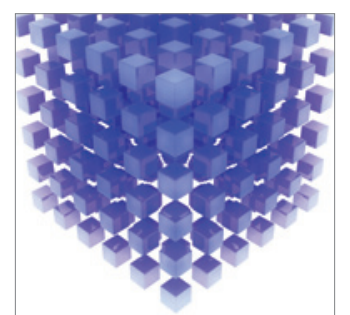

Mathematical Problems in Engineering
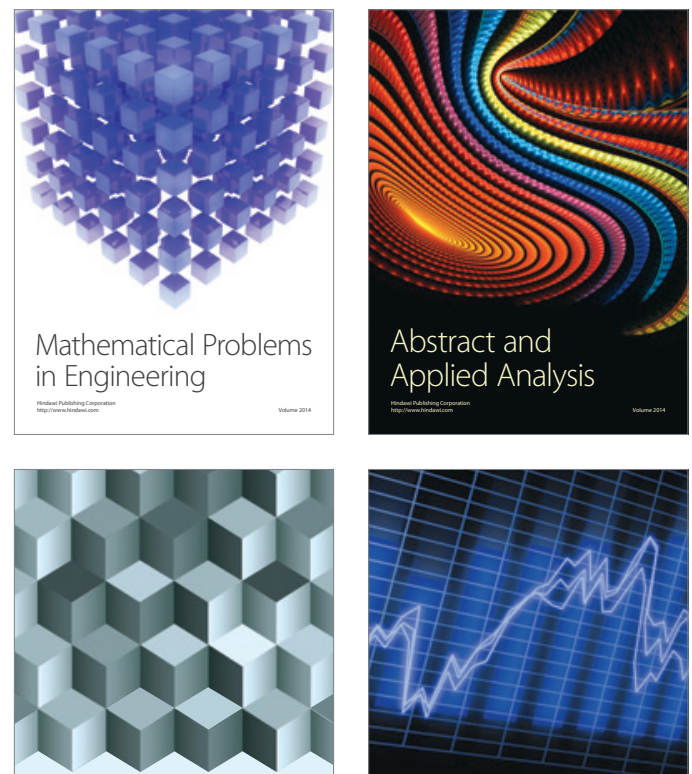

Journal of

Function Spaces

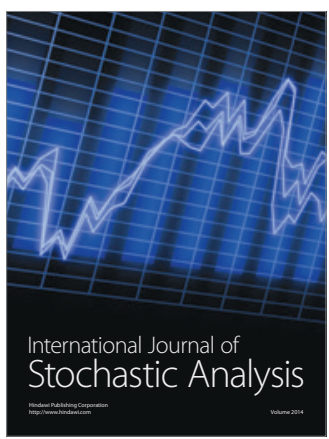

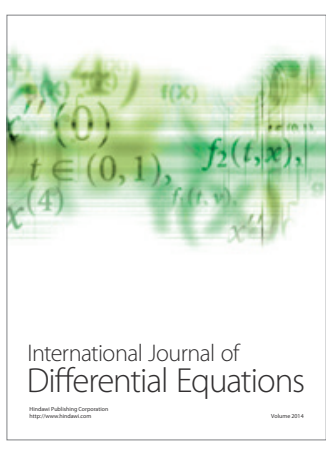
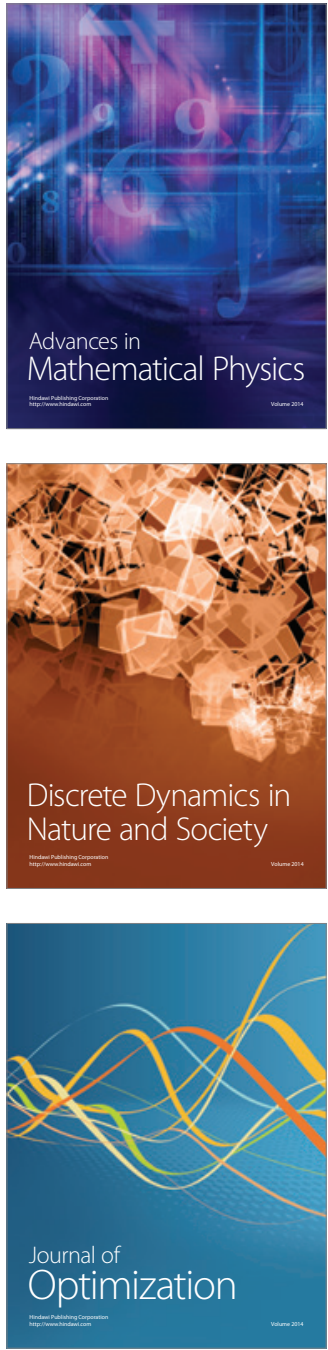